\title{
Optical whole-cell biosensor using Chlorella vulgaris designed for herbicides monitoring
}

\section{Christophe Védrine(1), J ean-Claude LeClerC $^{(2)}$, Claude DurRieU(3)*, CANH TRANH MiNH ${ }^{(1)}$}

(1) Ecole Nationale Supérieure des Mines de Saint Etienne, Centre SPIN ; Département PMMC ; 158, Cours Fauriel ; 42023 Saint-Étienne Cedex 2, France

(2) Université Jean Monnet, Equipe d'Ecophysiologie ; 23, Rue du Docteur Michelon, 42023 Saint-Étienne Cedex 2, France

(3) Ecole Nationale des Travaux Publics de l'Etat, Laboratoire des Sciences de l'Environnement ; 3, Rue Maurice Audin, 69518, Vaulx-en-Velin Cedex, France

\begin{abstract}
An optical biosensor was designed for determination of herbicides as aquatic contaminants. Detection was obtained with immobilised Chlorella vulgaris microalgae entrapped on a quartz microfibre filter and placed in a five-membrane-home-made-flow cell. The algal chlorophyll fluorescence modified by the presence of herbicides was collected at the tip of an optical fibre bundle and sent to a fluorimeter. A continuous culture was set up to produce algal cells in reproducible conditions for measurement optimisation. Effects of flow rate, algal density, temperature, and $\mathrm{pH}$ on the biosensor response to atrazine were studied. Reversibility and detection limits were determined for DNOC and atrazine, simazine, isoproturon, diuron. Detection of photosystem II (PSII) herbicides was achieved at sub-ppb concentration level.
\end{abstract}

Keywords:

Biosensor; Algae; Chlorella; Fluorescence; Herbicide; Ecotoxicology

\section{Introduction}

Pesticides determination has been a growing concern of agriculture and health care professionals and regulatory agencies. High-performance liquid chromatography (HPLC) or gas chromatography coupled with mass spectrometry (GC-MS) have required a preconcentration method (liquid-liquid extraction, solid-phase extraction...) for analysing pesticides in drinking water (Van der Hoff and Van Zoonen, 1999 and Hogendoorn and Van Zoonen, 2000). They demand skilled technicians, expensive equipment and are inappropriate for continuous monitoring. On the other hand, early-warning systems are needed in order to react in case of accidental pollution. Biosensors for pollutants determination have proved to be sensitive, low cost and easily adapted for on-line monitoring (Rogers, 1995). In addition, biosensors using whole cells are of ecotoxicity interest because these bioreceptors are the targets of numerous toxics.

Photosystem II (PSII)-based biosensors are reported to be able to detect herbicides in the environment (Giardi et al., 2001). Photosynthesis inhibition is an interesting indicator that rapidly reflects the toxic effect of pollutants ( Overnell, 1976). About 30\% of herbicides are targeting the vegetal PSII ( Moreland, 1980 and Draber et al., 1991). They include derivatives of phenylurea, triazine, and phenolic herbicides. These substances inhibit photosynthetic

\footnotetext{
*Corresponding author : durrieu@entpe.fr
} 
electron flow by blocking the PSII quinone binding site and thus modify chlorophyll fluorescence.

Some biosensing systems for herbicides detection use isolated chloroplasts or intact cells of algae to measure changes in chlorophyll fluorescence (Samson and Popovic, 1988; Arsalane et al., 1993; Conrad et al., 1993; Yoneyama et al., 1993; Merz et al., 1996; El Jay et al., 1997 and Van der Heever and Grobbelaar, 1998). These reagentless biosensors are compatible for in-field use or on line monitoring (Weston and Robinson, 1991; Frense et al., 1998 and Naessens et al., 2000). However, so far the limit of detection for atrazine reported with biosensors varied from 1 to $103 \mu^{\mathrm{g} \mathrm{l}^{-1}}$ depending on the bioreceptor used (Giardi et al., 2001). The objective of this study is to design a biosensor for on-line quality monitoring of groundwater and aquatic environment. Its performances should be close to European Community directive for herbicide detection ( $0.1 \mu \mathrm{g} \mathrm{l^{-1 }}$ for a single herbicide in drinking water). The concept of algal biosensor developed by Naessens et al. (2000) was adopted to design a new and reliable device for herbicides determination.

\section{Experimental}

\section{II.1. Solutions and reagents}

Herbicides were chosen for their global or specific activity on PSII. They include atrazine [2ethylamino-4-chloro-6-isopropyl amino-1,3,5 triazine], simazine [2,4-bis(ethylamino)-6chloro-1,3,5-triazine], diuron [3(3,4-dichlorophenyl)1,1 dimethylurea], isoproturon [3-(4isopropylphenyl)-1,1-dimethylurea], and dinitro-o-cresol (DNOC) [4,6-dinitro-2hydroxytoluene]. All herbicides (Pestanal () are purchased from Riedel-de-Haen (France). They are prepared in anhydrous ethanol (Carlo Erba) to get $10^{-3} \mathrm{M}$ stock solutions, which are stored in darkness at $4{ }^{\circ} \mathrm{C}$ for 1 month. All test solutions are diluted in Milli-Q® water (Millipore, France) immediately before use.

Four buffer solutions were required to investigate across the $3-10 \mathrm{pH}$ range. Citratephosphate $(\mathrm{pH} 3-5)$, phosphate $(\mathrm{pH} \mathrm{6-8)}$, boric acid-borax ( $\mathrm{pH} 9)$, borax- $\mathrm{NaOH}(\mathrm{pH} 10)$ buffer solutions were used at $10 \mathrm{mM}$ concentration. All chemicals were of analytical-reagent grade.

\section{II.2. Methods of investigation}

The Chlorella vulgaris strain (CCAP 211/12, Culture Collection of algae and protozoa, Cumbria, UK) was grown in the culture medium Lefebvre-Czarda described in the Guidance of International Organisation for Standardisation (ISO 8692). Cells were grown in a $300 \mathrm{ml}$ bioreactor that enables continuous culture (1500 lx, $12 \mathrm{~h}$ photo-period). During illumination, the reactor was supplied with medium while culture was removed at a same flow rate $(15 \mathrm{ml}$ $\mathrm{h}^{-1}$ ). Before each experiment using the biosensor, $15 \mathrm{ml}$ of fresh culture was harvested $5 \mathrm{~h}$ after the beginning of illumination.

The active membrane was constructed by physical entrapment of the algal cells onto a porous matrix. Immobilisation was achieved by simple filtration of an algal suspension on a quartz

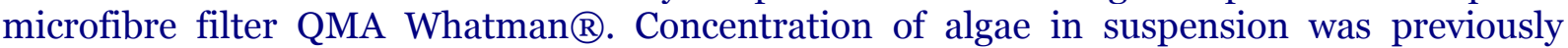
determined by optical density (OD) with a spectrophotometer Cary 300 (Varian, France) and counted under a microscope using a Thoma numeration cell (Polylabo, France). Typically, 20 $\mathrm{ml}$ of a suspension of $\mathrm{OD}=0.25$ at $760 \mathrm{~nm}$ (about $7 \times 10^{6}$ cells per ml) was used for a $11.3 \mathrm{~cm}^{2}$ membrane $(3.8 \mathrm{~cm}$ diameter). This membrane was punched to smaller discs $(8 \mathrm{~mm}$ in diameter, about $6 \times 10^{6} \mathrm{immobilised} \mathrm{cells)} \mathrm{that} \mathrm{fit} \mathrm{the} \mathrm{five} \mathrm{seatings} \mathrm{of} \mathrm{the} \mathrm{rotating} \mathrm{support.}$

\section{II.3. Construction of the algal optical biosensor}

A fibre-optic biosensor (Figure 1) was constructed with five removable algal membranes placed on a rotating support of a $10 \mathrm{ml}$ homemade flow cell. An electronically controlled motor rotated the support to position the membranes alternately in front of the tip of an optical fibre bundle. The incident light hits the upper part of the membrane and the resulting fluorescence radiation is collected up to the Spex Fluorolog 2 fluorometer (from Jobin-Yvon) equipped with a microcomputer for data recording. The flow running through the biosensor is 
temperature controlled using a thermostat (Lauda, Germany). Flow temperature inside the biosensor is monitored using a temperature probe (Checktemp2, Hanna instruments).

\section{II.4. Operating conditions}

Algal chlorophyll fluorescence measurement was carried out in two steps: $1 \mathrm{~min}$ to measure fluorescence, 4 min of darkness for the membrane to recover. While one membrane was in measurement position, the other four membranes were in stand-by position until the support rotates again. The excitation wavelength was set to $482 \mathrm{~nm}$ and the emission was measured at $683 \mathrm{~nm}$ : these wavelenghts are found optimal for fluorescence determination with C. vulgaris (CCAP 211/12).

An Ismastec peristaltic pump (Switzerland) was used to send a continuous flow of solution through the measurement device (Figure 1) between the five algal membranes and the optical fibre bundle. The sensor was first fed with a toxic-free solution (reference solution) for $14 \mathrm{~h}$ to get a stable fluorescence signal. Then a herbicide was introduced to measure the biosensor response. Reversibility of the biosensor response was tested after the reference solution ran through the biosensor again for $2 \mathrm{~h}$. Data were processed to obtain the mean fluorescence value (corresponding to $60 \mathrm{~s}$ of measurement) for each membrane.

Unless otherwise stated, all experiments were performed at $20^{\circ} \mathrm{C}$ in phosphate buffer solution ( $\mathrm{pH} 7,10 \mathrm{mM}$ ) with a $2 \mathrm{ml} \mathrm{min}^{-1}$ flow rate.

The biosensor long-term stability under on-line working conditions was carried out over 4 weeks. A $1 \mu \mathrm{g} \mathrm{l}^{-1}$ flow solution of atrazine was tested everyday for $1 \mathrm{~h}$ to determine the biosensor response, then a natural water flow (Volvic, France) was performed for $23 \mathrm{~h}$.

\section{Results and discussion}

III.1. Continuous cultivation of algal cells

A $300 \mathrm{ml}$ bioreactor was designed to have a continuous culture over 5 weeks. The medium flow rate had been adjusted so that the optical density (OD) at $760 \mathrm{~nm}$ remained at 0.5 (ca. $14 \times 10^{6}$ cells per $\mathrm{ml}$ ). A stable physiological activity is reached 4 days after the beginning of cultivation. This system provides fresh culture for everyday consumption. Harvested cells are in a same and optimal physiological state to improve reproducibility and sensitivity of herbicides detection. Moreover, the $C$. vulgaris continuous cultivation is very easy to set up and less time consuming compare with batch cultures.

Studies conducted on life cycles of a continuous and synchronous culture of Chlorella ellipsoidea (Tamiya, 1964) showed that cells harvested $5 \mathrm{~h}$ after the beginning of illumination are most photosynthetically active since they are derived from nascent cells. Similar results demonstrated that maximal quantum efficiency of photosynthesis was achieved between 2 and $8 \mathrm{~h}$ after the beginning of illumination for continuous cultures of Scenedesmus obliquus (Senger and Bishop, 1971) and Chlamydomonas reinhardii (Senger and Frickel-Faulstich, 1974). Samuelsson and Öquist (1977) have studied the DCMU-induced fluorescence at various stages of a Chlorella pyrenoidesa culture. They showed that maximal DCMU-induced fluorescence corresponded to a maximal photosynthesis activity. Considering these reported results, we have decided to harvest $C$. vulgaris cells $5 \mathrm{~h}$ after the beginning of illumination to ensure optimal physiological activity and biosensor parameters optimisation ( $\mathrm{pH}$, temperature...).

Additionally, the use of a continuous culture is a very convenient way to overcome problems link to culture of $C$. vulgaris.

\section{III.2. Detection principle}

Response of the algal biosensor was obtained from the chlorophyll fluorescence emission at 683 under $482 \mathrm{~nm}$ excitation light. These wavelengths were experimentally determined. Excitation maximum corresponds to the Soret band maximum absorption of chlorophyll $b$ (Hipkins and Baker, 1986) present in large amounts in green algae. Emission maximum corresponds to the main emission peak (fluorescent PSII band) for C. vulgaris (Govindjee and Satoh, 1986) and Scenedesmus subspicatus (Frense et al., 1998). 
This biosensor has been designed from practical considerations. This five membranes configuration enables to achieve a full time use of source and detector. Membranes are under the same conditions of light and toxic exposure. It results in good repeatability in membrane fluorescence measurement $(2.5 \%$ of standard deviation among five membranes using algae from the same continuous culture).

\section{III.3. Response of the biosensor}

The biosensor was tested in the absence of toxic compounds and in the presence of herbicides to compare their effects on fluorescence induction kinetics. The various steps characterising the algal biosensor response to herbicides have been described by Naessens et al. (2000). The presence of anti PSII herbicides (diuron, atrazine, simazine and isoproturon) increases the fluorescence emission. Reproducibility was assessed with three different continuous cultures. Five membranes of each were tested to obtain the standard deviation of the response to pollutant (6.5\%). Fourteen hours were needed to reach a stable fluorescence level. This fluorescence stability is required to detect any slight modification of the signal.

Figure 2 illustrates typical fluorescence signal change following an increase in atrazine concentration in the flow stream. The signal reaches a stable plateau for each addition of atrazine, so that a calibration curve can be plotted.

The biosensor response time necessary to attain 95\% maximal response was measured for flow rates comprise between $2 \mathrm{ml} \mathrm{min}^{-1}$ and $10 \mathrm{ml} \mathrm{min}^{-1}$ for $50 \mu \mathrm{g} \mathrm{l} \mathrm{l}^{-1}$ atrazine concentration. Since a time lag is required to bring the herbicide to the bioreceptor, response times decrease with increasing carrier flow rates (data not shown). At high flow rate, the overall response time tends to approach the effective biosensor response time, which is about $10 \mathrm{~min}$. This agrees with data reported by Frense et al. (1998).

\section{III.4. Effect of algal density on the biosensor behaviour}

The effect of algal loading in the membrane on the fluorescence signal (Figure 3) was assessed in good conditions since no leaching of algae was observed. When immobilised cells on the membrane increases, fluorescence increases and reaches a maximum corresponding to $15^{\times 10^{6}}$ cells. Then fluorescence decreases very slightly from $15 \times 10^{6}$ to $30 \times 10^{6}$ cells. This is attributed to part of the fluorescence reabsorbed by neighbouring algae.

To optimise biosensor response to atrazine in the range of $0.25-10 \mu \mathrm{g} \mathrm{l}^{-1}$, various concentrations of immobilised cells were tested (Figure 4). A maximal response corresponding to $6 \times 10^{6}$ immobilised cells on the membrane was observed for any atrazine concentrations and also for higher concentrations (up to $1 \mathrm{mg} \mathrm{l}^{-1}$, data not shown). The detection limit (a signal-to-noise of 3) corresponds to $0.4 \%$ of fluorescence increase. It can be conclude that the atrazine detection limit of this biosensor is $0.25 \mu \mathrm{g} \mathrm{l}^{-1}$ (inset Figure 4).

\section{III.5. Effect of temperature and $\mathrm{pH}$ on algal response to atrazine}

Effects of temperature and $\mathrm{pH}$ on the algal response were tested with two different concentrations of atrazine (50 and $\left.1000 \mu \mathrm{g} \mathrm{l}^{-1}\right)$.

The biosensor response to atrazine investigated from 10 to $30{ }^{\circ} \mathrm{C}$ (Figure 5) shows a maximum at $20{ }^{\circ} \mathrm{C}$. This also corresponds to the temperature used for algae cultivation conditions. Good response between 10 and $25^{\circ} \mathrm{C}$ still allow sensitive determination of atrazine. However, the sensor response is very affected beyond $25{ }^{\circ} \mathrm{C}$ for any atrazine concentrations and measurement in this region should be avoided.

The pHs tested ranges from 3 to 10 (Figure 6). Considering the various buffers involved, low buffer solution concentrations were used to minimise the effect of buffer composition on algae metabolism. Maximum response is achieved at $\mathrm{pH} 7$, which corresponds to the culture medium pH. Between $\mathrm{pH} 5$ and 9 the biosensor response is high enough to ensure sensitive determination of atrazine. Maximal response is reduced by half for $\mathrm{pH} 3$ and 10. To monitor atrazine in water, the $C$. vulgaris biosensor should operate as close to the optimal conditions as possible ( $\mathrm{pH} 7$ and $20^{\circ} \mathrm{C}$ ) to achieve best results. 


\section{III.6. Long-term stability under on-line working conditions}

The main objective of algae immobilisation is to stabilise the bioreceptor for the biosensor to be used repeatedly over a long period of time under on-line monitoring conditions.

No loss of activity participating to the biosensor response had been observed. The response of the biosensor to $1 \mu \mathrm{g} \mathrm{l}^{-1}$ of atrazine remains stable over 4 weeks (data not shown).

III.7. Detection limit and $\mathrm{EC}_{50}$

One of our objectives was to improve the detection limit with a $C$. vulgaris based biosensor. Atrazine was first tested to determine optimal operating conditions, which were later applied for other herbicides. Dose response curves corresponding to atrazine, simazine, diuron and isoproturon are presented in Figure 7. Successive addition method is not appropriate to construct DNOC response curve due to its dual mode of action. The detection limit, the toxic concentration $\mathrm{EC}_{50} \mathrm{O}$ that affects $50 \%$ of the response and reversibility of action of these pollutants are listed in Table 1.

Triazines and phenylurea are well-known herbicides that specifically fix to the $\mathrm{Q}_{\mathrm{B}}$ binding site of PSII with high affinity. This blocks the photosynthetic electron flow and causes an increase in chlorophyll fluorescence intensity. Experiments performed with atrazine, simazine, isoproturon and diuron (classical PSII inhibitors) showed that the biosensor was very sensitive to all four herbicides at sub ppb level. The $\mathrm{EC}_{50}$ obtained is consistent with the detection limit (the lower the $\mathrm{EC}_{50}$, the lower the limit of detection). Those herbicides can be considered as reversible since most activity is recovered after exposition to herbicides and flushing the biosensor with a reference solution.

Phenolic herbicides have two modes of action: they are inhibitors of PSII electron transport, and also uncouplers of oxidative phosphorylation and photophosphorylation, due to their protonophoric properties (Oettmeier et al., 1987). This could explain the specific behaviour of the biosensor towards the phenolic herbicide, DNOC. The fluorescence intensity increases until $300 \mu \mathrm{g} \mathrm{l}^{-1}$. It could be attributed to the inhibition of PSII electron transport while the uncoupling effect is comparably negligible. Although the PSII inhibition still increases at higher concentrations, the uncoupling effect of DNOC tends to become the major parameter, which decreases fluorescence signal. Although DNOC is a poor inhibitor of PSII electron transport compared with triazine, phenyl-urea and others from the same family (dinoseb, dinoterb, ioxynil) (Scalla and Gauvrit, 1991), it can be detected down to $5 \mu \mathrm{g} \mathrm{l}^{-1}$ (Table 1). It should be noted that the phytotoxicity of DNOC is mainly due to its uncoupling effect rather than inhibition effect on PSII electron transport ( Scalla and Gauvrit, 1991).

Since its mode of action, modification of fluorescence signal is irreversible. Rinsing the biosensor with a DNOC free solution results in a decrease of the fluorescence signal far below the reference level suggesting that the membrane has been damaged due to the uncoupling effect while PSII inhibition is no longer effective. In case of herbicides monitoring, precaution should be taken in interpretation of the response particularly if DNOC concentration exceeds $300 \mu \mathrm{gl}^{-1}$.

\section{Conclusion}

The fluorescence-based biosensor using $C$. vulgaris is particularly suitable for detection of PSII-inhibiting herbicides. It can also be used for determination of other herbicides such as DNOC, which is a poor inhibitor of PSII electron transport.

Two strategies have been adopted to improve the performance of this biosensor. First, optimisation of the bioreceptor is achieved with a continuous cultivation technique, which provides harvested cells in a same optimal physiological state that increases reproducibility. Thus it facilitates the determination of optimal operating conditions (algal density on the membrane, $\mathrm{pH}$, temperature) and results in an improvement of pollutant detection. This strategy has never been reported (to our knowledge) for biosensors using C. Vulgaris. Second, reliability of the sensor to detect pollutants is improved as the number of assays performed is multiplied by five compared with a single membrane based biosensor. This design enables an 
easier monitoring of the evolution of the flow toxicity because of the $1 \mathrm{~min}$ lag difference between the measurement of each membrane.

Response time and detection limit of this biosensor are compatible for groundwater and aquatic environment quality monitoring and its use as an early warning system. In fact, the level of atrazine in river water varies seasonally with the highest concentrations found in the spring and summer months (Solomon et al., 1996). For example, Hall et al. (1993) reported detectable levels of atrazine rapidly rose to $43 \mu \mathrm{g} \mathrm{l} \mathrm{l}^{-1}$ during May and then dropped sharply to $1.8 \mu \mathrm{g} \mathrm{l}^{-1}$ by the end of June. The biosensor would be an appropriate tool to monitor seasonal variation of atrazine in aquatic media and be used as an alarm system. Further investigations with several micro-organisms tested simultaneously in this multi-membrane device would give a better understanding of the impact of pollutants on aqueous ecosystems.

\section{References}

Arsalane, A., Parésys, G., Duval, J.-C., Wilhelm, C., Conrad, R. and Büchel, C., 1993. A new fluorometric device to measure the in vivo chlorophyll a fluorescence yield in microalgae and its use as a herbicide monitor. Eur. J. Phycol. 28, pp. 247-252.

Conrad, R., Büchel, C., Wilhelm, C., Arsalane, W., Berkaloff, C. and Duval, J.C., 1993. Changes in yield of in vivo fluorescence of chlorophyll a as a tool for selective herbicide monitoring. J. Appl. Phycol. 5, pp. 505-516.

Draber, W., Tietjen, K., Kluth, J.F. and Trebst, A., 1991. Herbicides in photosynthesis research. Angew. Chem. Int. Ed. Engl. 30, pp. 1621-1633.

El Jay, A., Ducruet, J.M., Duval, J.C. and Pelletier, J.P., 1997. A high-sensitivity chlorophyll fluorescence assay for monitoring herbicide inhibition of photosystem II in the chlorophyte Selenastrum capricornutum: comparison with effect on cell growth. Arch. Hydrobiol. 140, pp. 273-286.

Frense, D., Müller, A. and Beckmann, D., 1998. Detection of environmental pollutants using optical biosensor with immobilised algae cells. Sens. Actuat. B 51, pp. 256-260.

Giardi, M.T., Koblizek, M. and Masojidek, J., 2001. Photosystem II-based biosensors for the detection of pollutants. Biosens. Bioelectron. 16, pp. 1027-1033.

Govindjee and Satoh, K., 1986. Fluorescence properties of chlorophyll $b$ - and chlorophyll $c$ containing algae. In: Govindjee, Amesz, J. and Fork, D.C., Editors, 1986. Light Emission by Plants and Bacteria, Academic Press, Orlando, pp. 497-537.

Hall, J.C., Van Deynze, T.D., Struger, J. and Chan, C.H., 1993. Enzyme immunoassay based survey of precipitation and surface water for the presence of atrazine, metolachlor and 2,4-D. J. Environ. Sci. Health 28 Part B, pp. 577-598.

Hipkins, M.F. and Baker, N.R., 1986. Spectroscopy. In: Hipkins, M.F. and Baker, N.R., Editors, 1986. Photosynthesis Energy Transduction. A Practical Approach, Irl Press, Oxford, pp. 51-101.

Hogendoorn, E. and Van Zoonen, P., 2000. Recent and future developments of liquid chromatography in pesticide trace analysis. J. Chromatogr. A 892, pp. 435-453.

Merz, D., Geyer, M., Moss, D.A. and Ache, H.-J., 1996. Chlorophyll fluorescence biosensor for the detection of herbicides. Fresenius J. Anal. Chem. 354, pp. 299-305.

Moreland, D.E., 1980. Mechanisms of action of herbicides. Annu. Rev. Plant Physiol. 31, pp. 597-638.

Naessens, M., Leclerc, J.-C. and Tran-Minh, C., 2000. Fiber optic biosensor using Chlorella vulgaris for determination of toxic compounds. Ecotoxicol. Environ. Saf. 46, pp. 181185.

Oettmeier, W., Kude, K. and Soll, H.-J., 1987. Phenolic herbicides and their methyl-ethers: binding characteristics and inhibition of photosynthetic electron transport and photophosphorylation. Pestic. Biochem. Physiol. 27, pp. 50-60.

Overnell, J., 1976. Inhibition of marine algal photosynthesis by heavy metals. Mar. Biol. 38, pp. 335-342.

Rogers, K.R., 1995. Biosensors for environmental applications. Biosens. Bioelectron. 10, pp. 533-541. 
Samson, G. and Popovic, R., 1988. Use of algal fluorescence for determination of phytotoxicity of heavy metals and pesticides as environmental pollutants. Ecotoxicol. Environ. Saf. 16, pp. 272-278.

Samuelsson, G. and Öquist, G., 1977. A method for studying photosynthetic capacities of unicellular algae based on in vivo chlorophyll fluorescence. Physiol. Plant 40, pp. 315319 .

Scalla, R. and Gauvrit, C., 1991. Mécanismes d'action phytotoxique des autres familles d'herbicides. In: Scalla, R., Editor, , 1991. Les herbicides: mode d'action et principes d'utilisation, Inra, Paris, pp. 115-191.

Senger, H. and Bishop, N., 1971. Changes in fluorescence and absorbance during synchronous growth of Scenedesmus. In: Forti, G., Avron, M. and Melandri, A., Editors, 1971. Proceedings of the Second International Congress on Photosynthesis, Stresa, The Hague, pp. 677-687.

Senger, H. and Frickel-Faulstich, B., 1974. The regulation of electron flow in synchronized cultures of green algae. In: Avron, M., Editor, , 1974. Proceedings of the Third International Congress on Photosynthesis, Elsevier, Rehovot, Israel, pp. 715-727.

Solomon, K.R., Baker, D.B., Richards, R.P., Dixon, K.R., Klaine, S.J., La Point, T.W., Kendall, R.J., Weisskoff, C.P., Giddings, J.M., Giesy, J.P., Hall, L.W. and Williams, W., 1996. Ecological risk assessment of atrazine in North American surface waters. Environ. Toxicol. Chem. 15, pp. 31-76.

Tamiya, H., 1964. Growth and cell division of Chlorella. In: Zeuthen, E., Editor, , 1964. Synchrony in Cell Division and Growth, Interscience Publishers, New York, pp. 247305 .

Van der Heever, J.A. and Grobbelaar, J.U., 1998. In vivo chlorophyll A fluorescence of Selenastrum capricornutum as a screening bioassay in toxicity studies. Arch. Environ. Contam. Toxicol. 35, pp. 281-286.

Van der Hoff, R.G. and Van Zoonen, P., 1999. Trace analysis of pesticides by gas chromatography. J. Chromatogr. A 843, pp. 301-322.

Weston, L. and Robinson, P., 1991. Detection and quantification of triazine herbicides using algal cell fluorescence. Biotechnol. Tech. 5, pp. 327-330.

Yoneyama, K., Nakajima, Y., Maejima, N., Ogasawara, M., Konnai, M., Tokutake, N., Iwamura, H., Sato, F., Ichinose, K., Asami, T. and Yoshida, S., 1993. Simple and rapid screening method for photosystem II inhibitory herbicides using photoautotrophically cultured plant cells with chlorophyll fluorescence monitoring. Biosci. Biotech. Biochem. 57, pp. 1389-1390. 


\section{Figures}

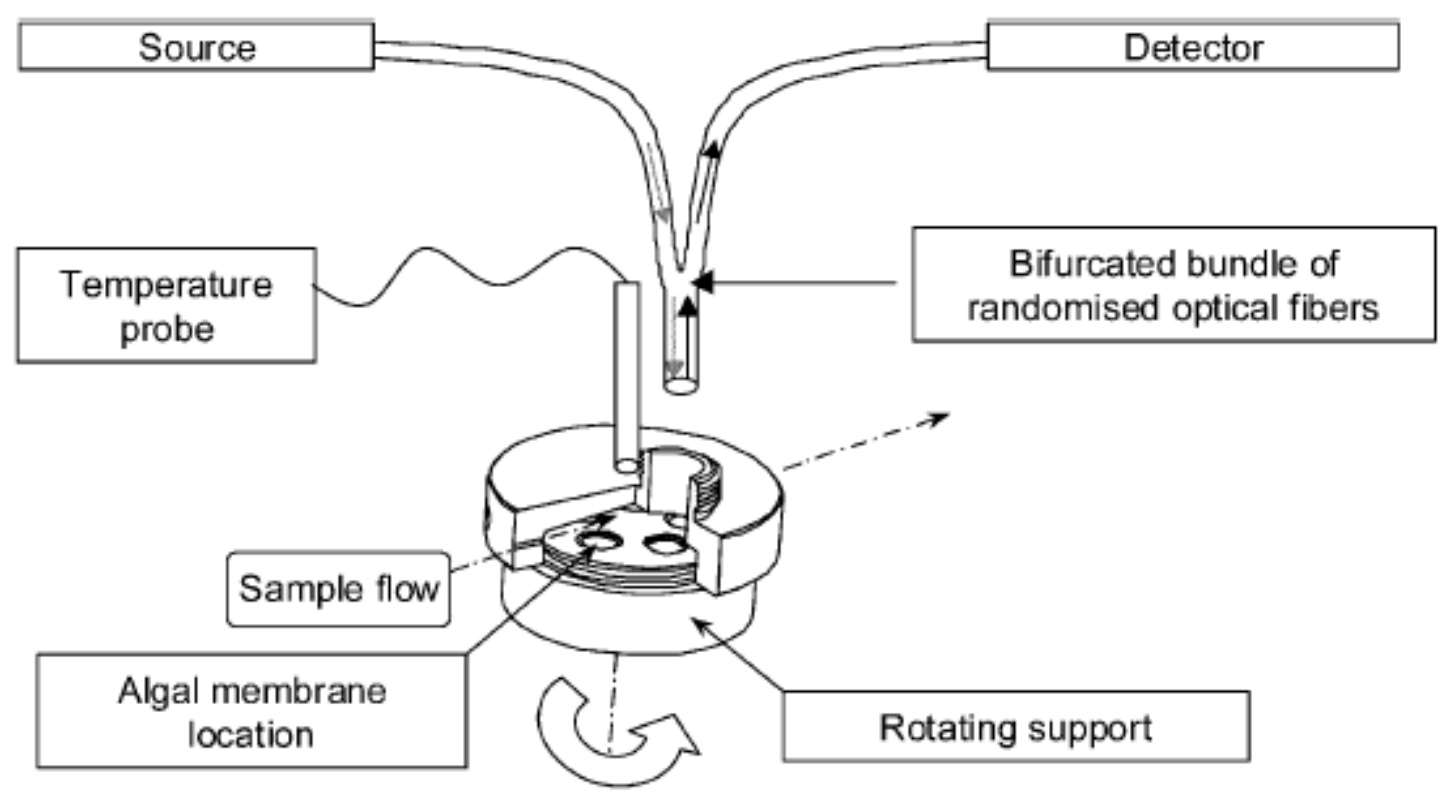

Figure 1: Experimental set-up of the algal optical biosensor for continuous toxicity assessment.

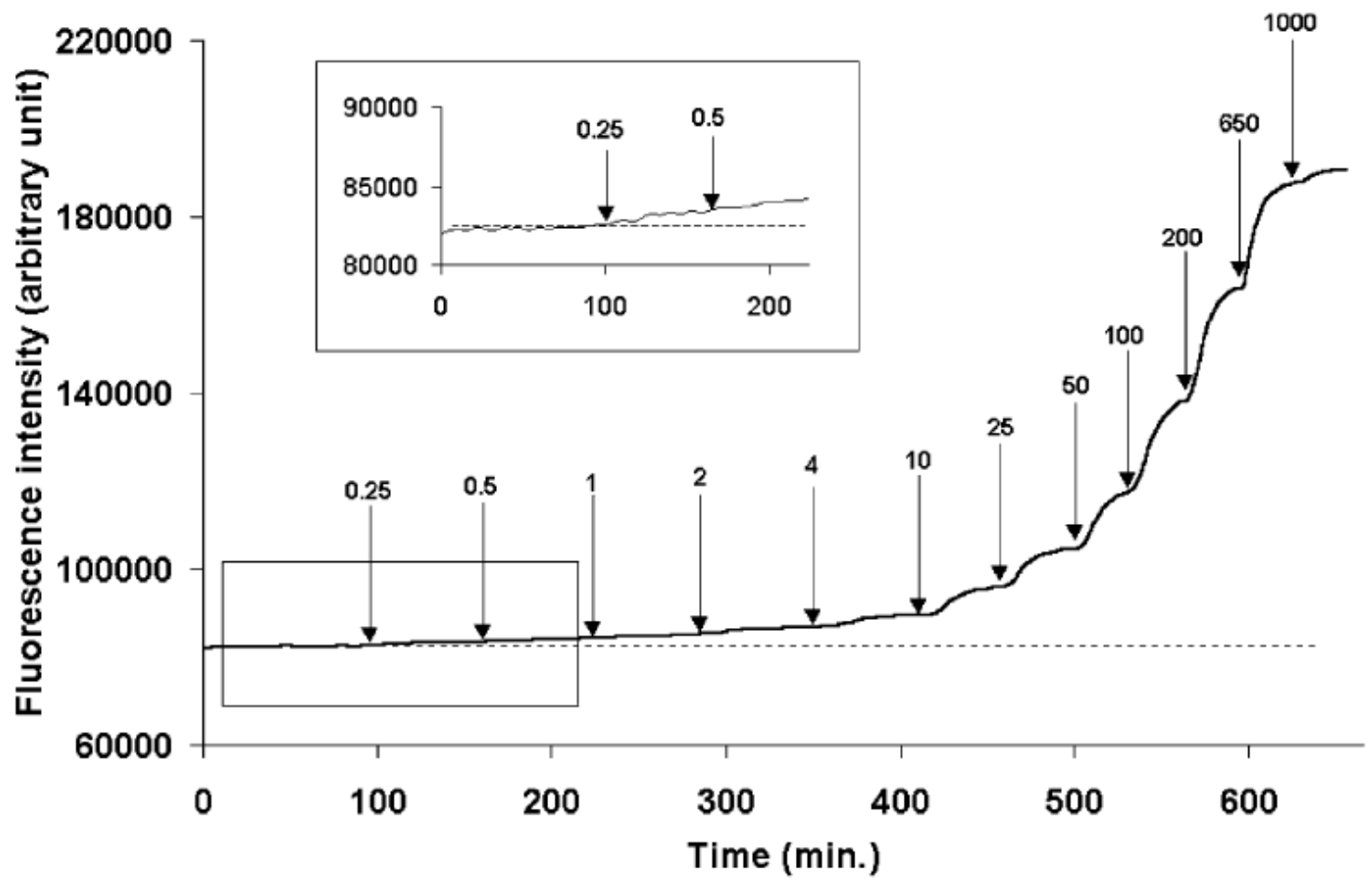

Figure 2: Typical response of a C. vulgaris membrane to increasing concentrations of atrazine ( $\mu$ g $\left.l^{-1}\right)$. Inset: response for low concentrations of atrazine, (----) fluorescence base-line. Conditions: $10 \mathrm{mM}, \mathrm{pH}$ 7.o phosphate buffer, $2 \mathrm{O}^{\circ} \mathrm{C}, 2 \mathrm{ml} \mathrm{min}^{-1}$ flow rate. 


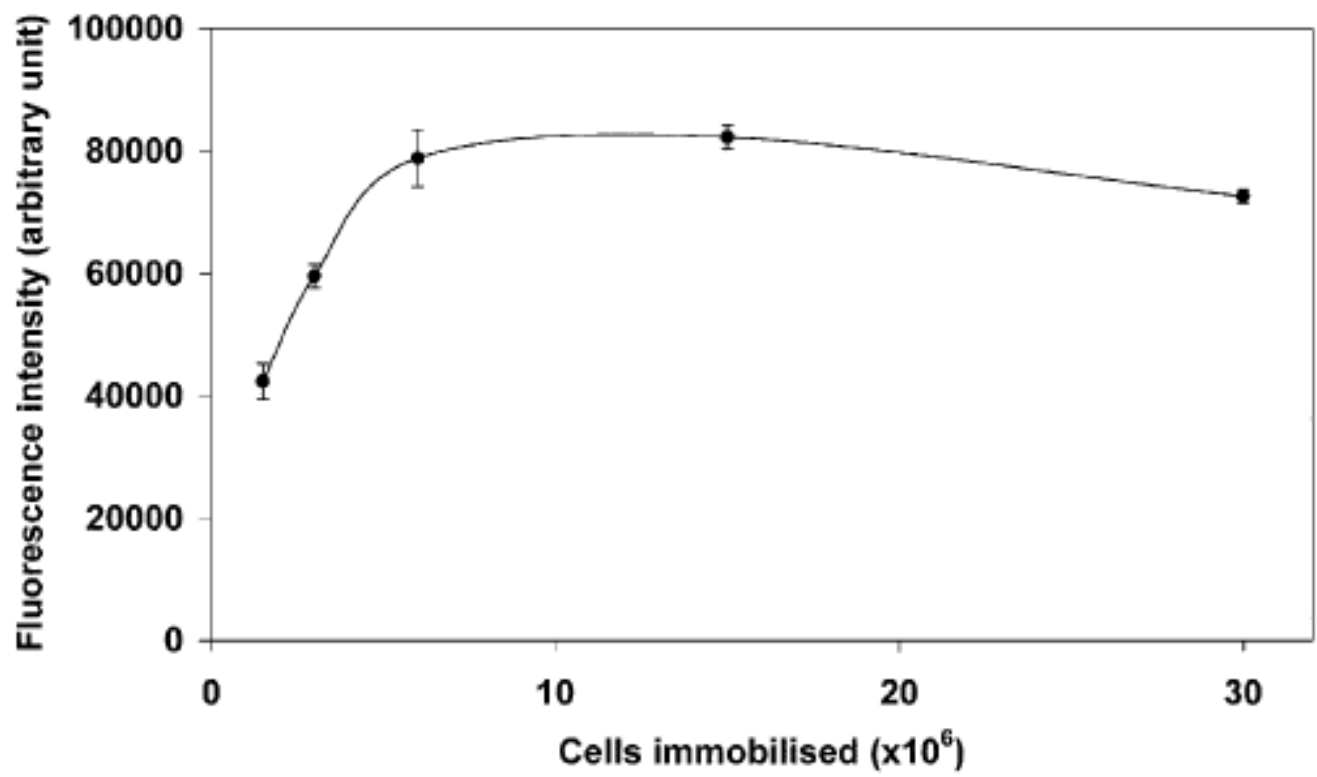

Figure 3: Effect of algal loading on chlorophyll fluorescence of C. vulgaris. Mean values from three membranes corresponding to three different continuous cultures were used to obtain this curve. Conditions: $10 \mathrm{mM}, \mathrm{pH} 7.0$

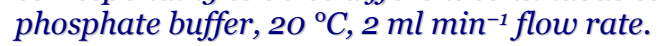

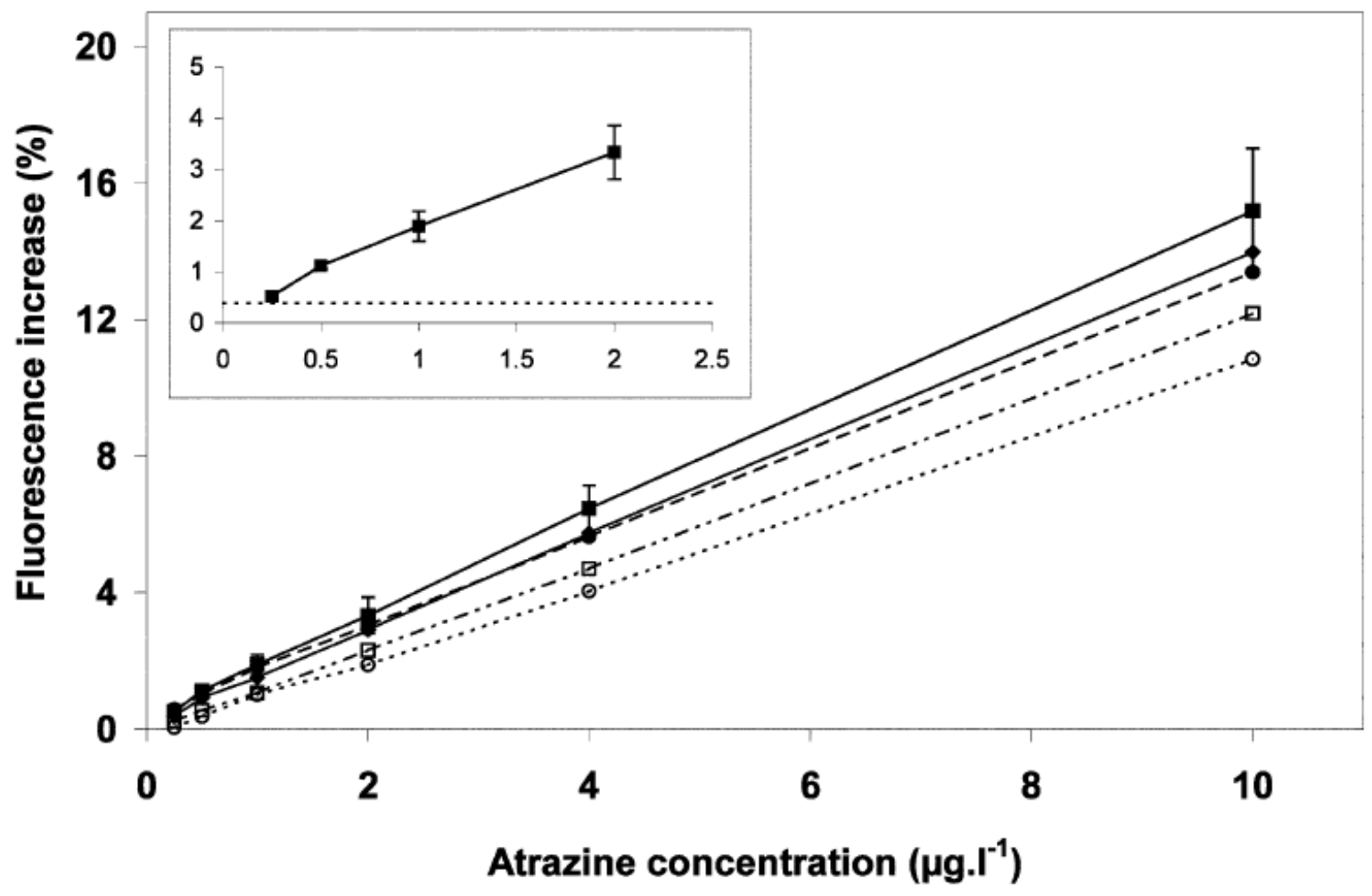

Figure 4: Effect of algal loading: $1.5 \times 10^{6}(\circ), 3 \times 10^{6}(\bullet), 6 \times 10^{6}(\cdot), 15 \times 10^{6}(\bullet), 30 \times 10^{6}(\square)$ cells per membrane on the sensor response to low concentrations of atrazine. Inset: response for atrazine concentration around ppb level for $6 \times 10^{6}$ immobilised cells per membrane and detection limit (-----). Mean values from three membranes corresponding to three different continuous cultures were used to obtain these curves. Conditions: $10 \mathrm{mM}, \mathrm{pH} 7.0$

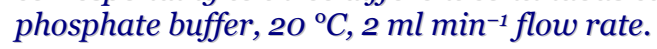




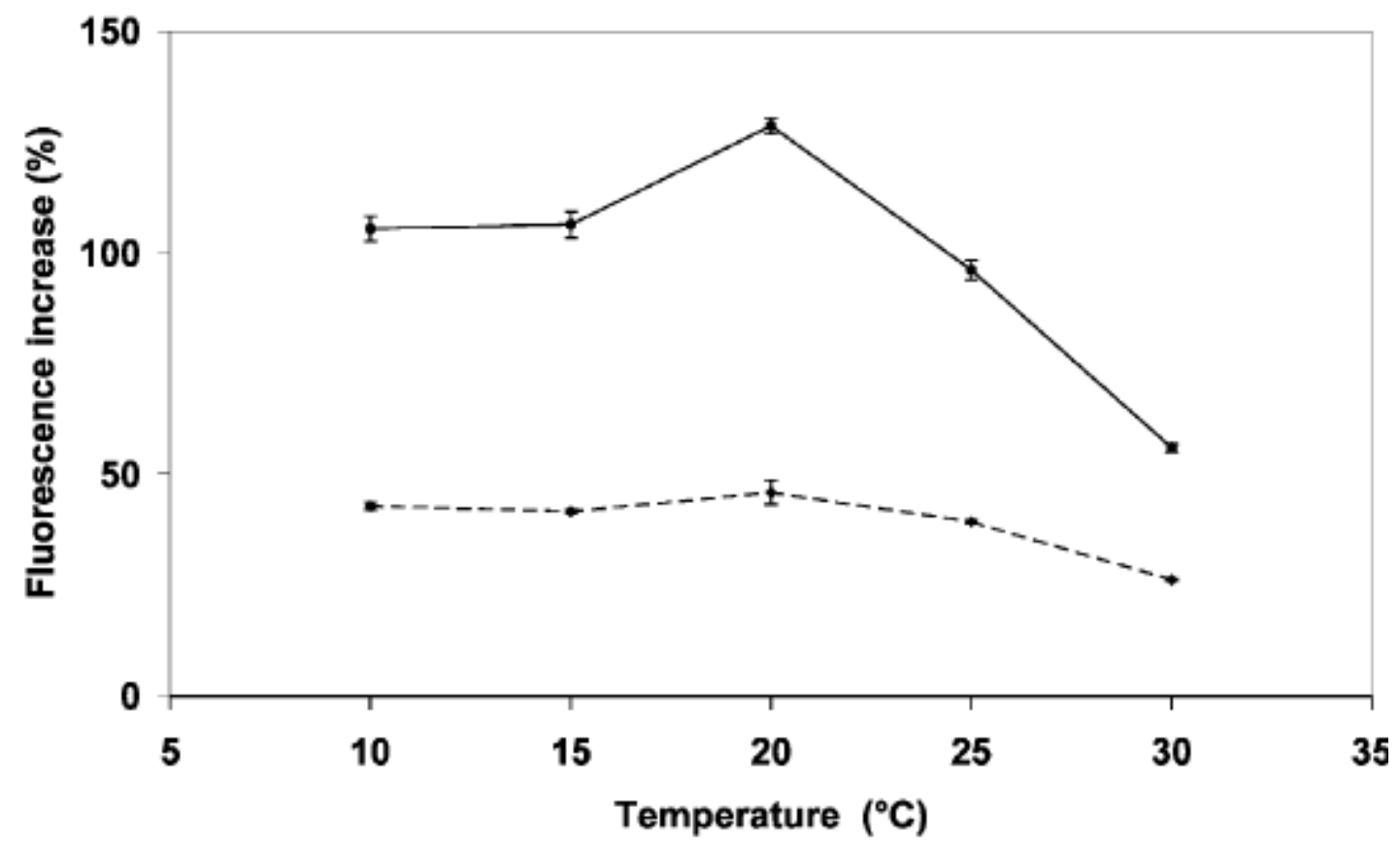

Figure 5: Effect of temperature on the sensor response to $50 \mu \mathrm{gl}^{-1}(----)$ and $1000 \mu \mathrm{g} \mathrm{l}^{-1}(-)$ of atrazine. Mean values from three membranes corresponding to three different continuous cultures were used to obtain the curves. Conditions: $10 \mathrm{mM}, \mathrm{pH} 7.0$ phosphate buffer, $2 \mathrm{ml} \mathrm{min}^{-1}$ flow rate.

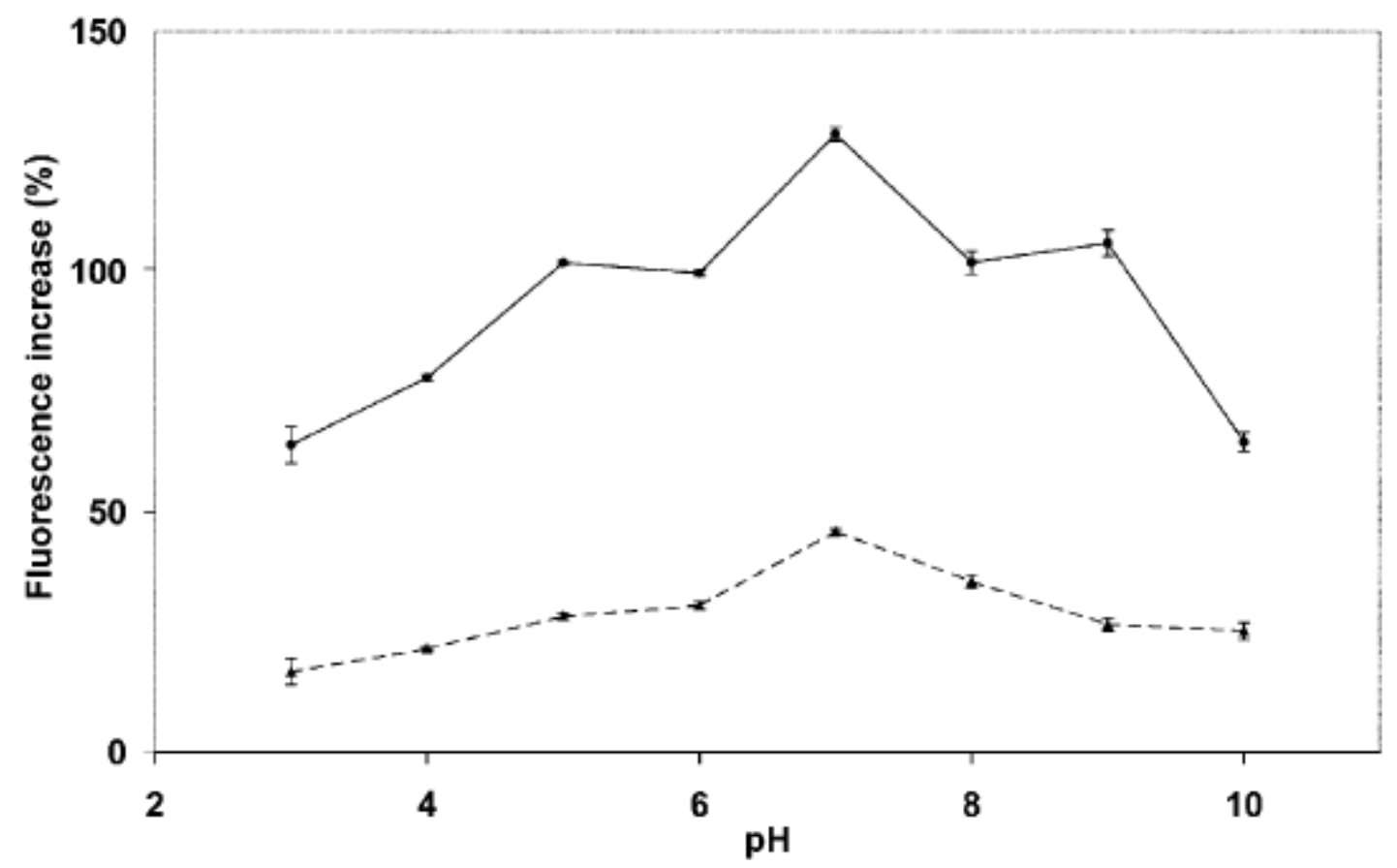

Figure 6: Effect of $\mathrm{pH}$ on the sensor response to $50 \mu \mathrm{g}^{-1}$ (-----) and $100 \mathrm{og} \mathrm{l}^{-1}$ (-) of atrazine. Mean values from three membranes corresponding to three different continuous cultures were used to obtain the curves. Conditions: $10 \mathrm{mM}$, pH 3.O-5.O citrate-phosphate buffer, pH 6.o-8.o phosphate buffer, pH 9.o boric acid-

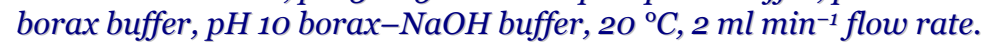




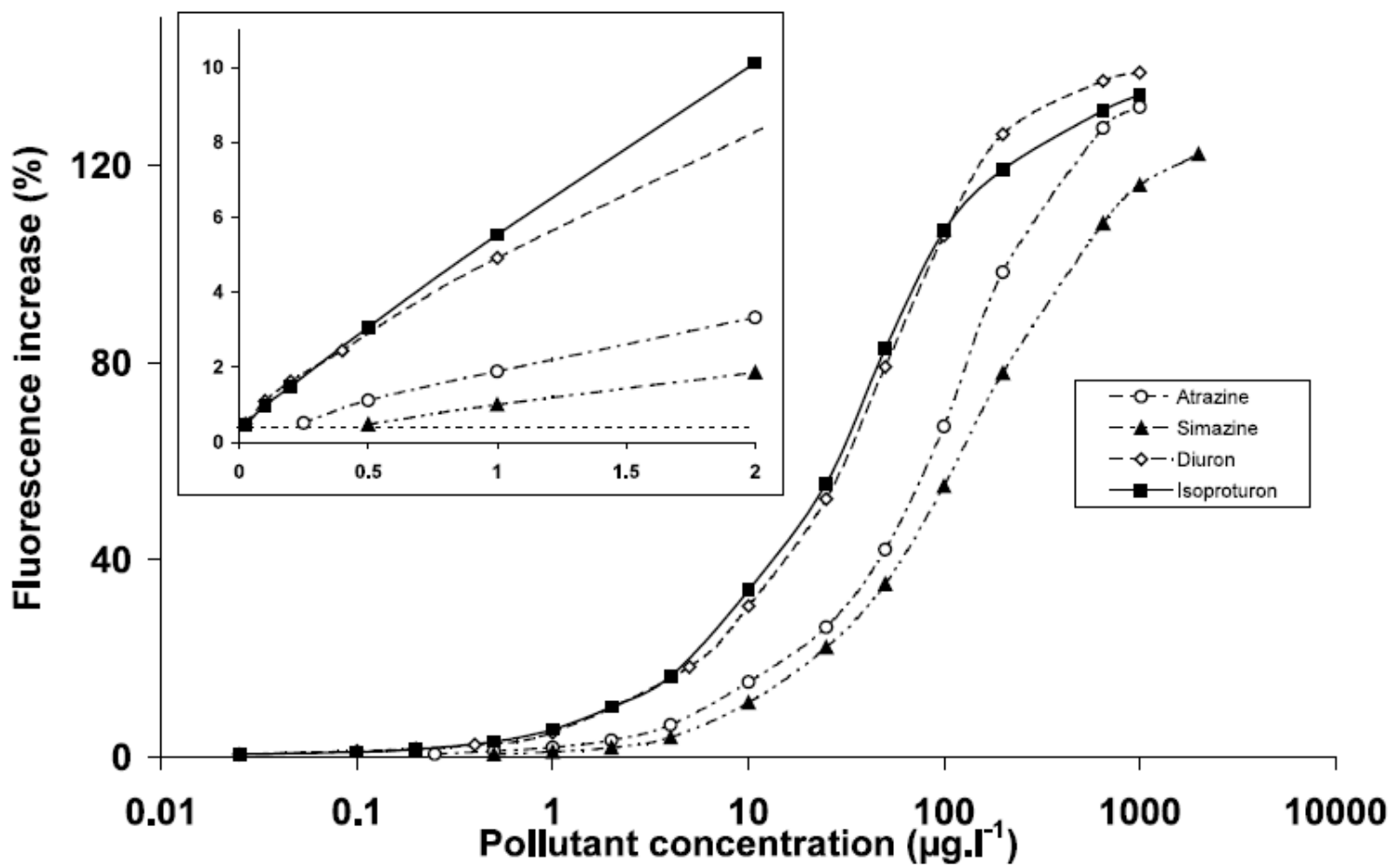

Figure 7: Dose-response curves for the detection of herbicides with chlorophyll fluorescence measurement (logarithmic scale for pollutant concentration). Inset: response for pollutant concentration (linear scale) around ppb level and detection limit (----). Conditions: $10 \mathrm{mM}, \mathrm{pH} 7.0$ phosphate buffer, $2 \mathrm{O}^{\circ} \mathrm{C}, 2 \mathrm{ml} \mathrm{min}^{-1}$ flow rate.

\section{Tables}

Table 1: Characteristics of the algal optical biosensor response to different herbicides. Mean values obtained from 9 membranes (with 3 different continuous cultures)

\begin{tabular}{|l|l|l|l|}
\hline Herbicides & $\begin{array}{l}\text { Detection limit }\left(\mathrm{mg} \mathrm{l}^{-1}\right) \\
\text { (signal-to-noise of } 3)\end{array}$ & EC5O $\left(\mathrm{mg} \mathrm{l}^{-1}\right)$ & Reversibility \\
\hline Atrazine & 0.25 & $96 \pm 4$ & Yes \\
\hline Simazine & 0.5 & $127 \pm 4$ & Yes \\
\hline Isoproturon & 0.025 & $35 \pm 4$ & Yes \\
\hline Diuron & 0.025 & $39 \pm 4$ & Yes \\
\hline DNOC & 5 & - & No \\
\hline
\end{tabular}

